\title{
Design Of Compact 180 Degree Hybrid Coupler Using T-shape Structure.
}

\author{
B. Pavithra ${ }^{1}$, Dr.S.Maheswari ${ }^{2}$ \\ PG Student ${ }^{1}$, Professor ${ }^{2}$, Department of Electronics and Communication Engineering \\ Panimalar Engineering College,Chennai, India \\ pavipavithra509@gmail.com,maheswarisp@yahoo.co.in
}

\begin{abstract}
The Hybrid couplers are the bidirectional couplers which can give equal power split and $180^{\circ}$ phase shift between the two output ports. At lower frequencies the size of the rat race coupler becomes larger. Hence, the size of hybrid coupler should be reduced in order to agree with application requirements. Reduction of hybrid coupler size is achieved by replacing each $\frac{\lambda}{4}$ section using $T$-shape structures for different characteristic impedance. The hybrid ring with T-shape structure and conventional hybrid coupler is compared. By using $T$ - shape structure $88 \%$ of size reduction has been achieved.
\end{abstract}

Keywords - Hybrid coupler using T-shape structure; Hybrid Coupler;

\section{INTRODUCTION}

The rat-race hybrid ring is an important structure in microwaves. It is a four port junction with 180 degree phase shift between two ports[1]. The mono-pulse comparator uses four hybrid couplers and gathers angular position from one pulse[2]. The port which providing the out-of phase division is called as $\Delta$-port and the one providing is in phase signal division called as $\sum$-port[3].

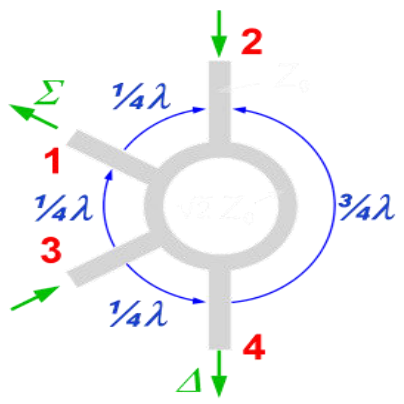

Figure 1. 180 degree hybrid coupler

A ring coupler consists of line of electrical length which contains standing waves, to which four arms are connected at interval [4]. The Rat- race coupler has two main disadvantages which is difficult to solve.

Initially, the undesired interference occur when conventional rat- race coupler work at its odd harmonics [6].

The Microstrip hybrid coupler is designed by applying the conventional hybrid coupler using T-shape structure. The designed structure can achieve both reduction of size and undesired interference.
The efficient devices operating in high data rate and low power signal are used in wireless Technology. The researchers working on development of RF technology to get that result. In order to meet the circuit miniaturization in wireless communication, it requires smaller device size. Thus, size reduction becoming major design requirement for practical applications.

\section{RAT-RACE HYBRID COUPLER}

The conventional rat-race coupler has four ports, each placed $\frac{\lambda}{4}$ length away from each other around one half of the ring. The another half of the ring is $\frac{3 \lambda}{4}$ in length. The characteristic impedance of ring should be $\sqrt{2}$ times the characteristic impedance of the ports. If using port 2 as input ports, equal phase and amplitude signals emerge from port 1 $\&$ port 3 and port 4 is isolated. If using port 1 as input port, equal phase and amplitude signals emerge from port $2 \&$ port 4 and port 3 is isolated. When used as a power combiner, signals are fed to port $1 \&$ port 3 . Difference signals available at port 4 and sum signals are available at port 2 . If input is fed on port 1 and output signals will split at ports 2 and 4 and port 3 will be isolated. The rat-race circuit is used for combining two different signals or dividing the signals into two signals. The port which providing the out-of phase division is called as $\Delta$-port and the one providing is in phase signal division called as $\sum$-port. The scattering matrix for conventional rat-race coupler is

$$
S=\frac{-i}{\sqrt{2}}\left(\begin{array}{cccc}
0 & 1 & 0 & -1 \\
1 & 0 & 1 & 0 \\
0 & 1 & 0 & 1 \\
-1 & 0 & 1 & 0
\end{array}\right)
$$

Figure 2. Rat-Race Hybrid Coupler

The rat-race coupler is used in many microwave devices such as power amplifiers, mixers, antenna systems, bandwidth in power dividing distribution, and a high isolation between the ports. Satellite communication, phased array radar antenna systems and radar are some applications where rat-race couplers are used widely. 


\section{HYBRID RING USING T-SHAPE STRUCTURE}

The size of the hybrid coupler is reduced using T-shape structure by considering the $\frac{\lambda}{4}$ length transmission line to be implemented using $\mathrm{T}$ - shape structure as shown. Hence, the ABCD parameters of $\frac{\lambda}{4}$ length transmission line and $\mathrm{T}$ shape structure should be same.

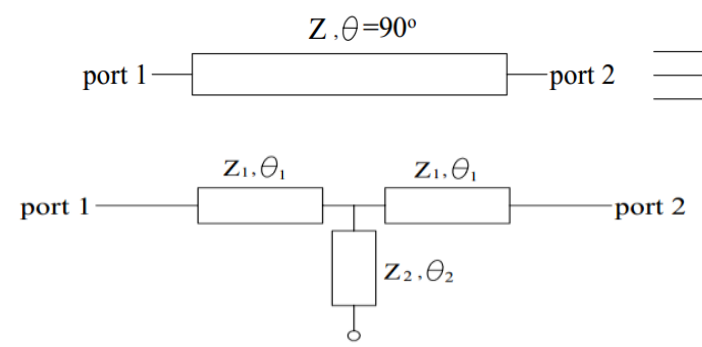

Figure 3. $\frac{\lambda}{4}$ length transmission line and its equivalent T-shape structure

The line $\left(Z_{2}, \theta_{2}\right)$ is represented as open circuited shunt stub which is shown. By knowing the $\left(Z_{2}, \theta_{2}\right)$ line, the ABCD parameters of the $\mathrm{T}$-shape structure can be found. The shunt stub specified above is replaced by shunt impedance $Z_{\text {shunt }}$, where,

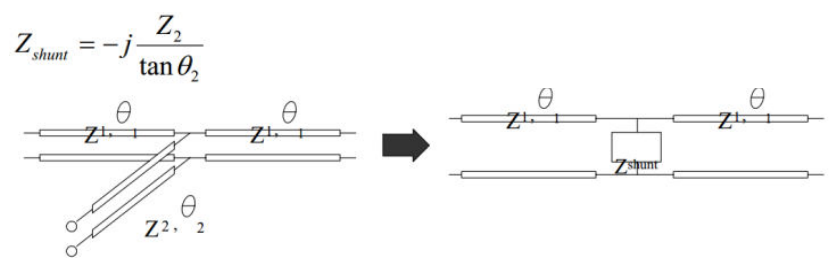

Figure 4. T-shaped structure and shunt impedance is replaced instead of shunt stub.

The ABCD matrix for the above given shunt impedance is given as:

$$
\left[\begin{array}{ll}
A & B \\
C & D
\end{array}\right]=\left[\begin{array}{cc}
1 & 0 \\
\frac{1}{Z_{\text {shunt }}} & 1
\end{array}\right]=\left[\begin{array}{cc}
1 & 0 \\
j \frac{1}{Z_{2}} \tan \theta_{2} & 1
\end{array}\right]
$$

Similarly, the ABCD matrix calculated for the T-shape structure is expressed as

$$
\left[\begin{array}{ll}
A & B \\
C & D
\end{array}\right]=\left[\begin{array}{cc}
\cos \theta_{1} & j Z_{1} \sin \theta_{1} \\
j \frac{1}{Z_{1}} \sin \theta_{1} & \cos \theta_{1}
\end{array}\right]\left[\begin{array}{cc}
1 & 0 \\
j \frac{1}{Z_{2}} \tan \theta_{2} & 1
\end{array}\right]\left[\begin{array}{cc}
\cos \theta_{1} & j Z_{1} \sin \theta_{1} \\
j \frac{1}{Z_{1}} \sin \theta_{1} & \cos \theta_{1}
\end{array}\right]
$$

The values of $\theta_{1}$ and $\theta_{2}$ and total electrical length $\theta_{T}$ is calculated using

$$
\theta_{T}=2 \theta_{1}=2 \tan ^{-1}\left(\frac{1}{M}\right)
$$

The total electrical length value depend only on M. From the above statement it states that the total electrical length decreases as $\mathrm{M}$ increases but for certain $\mathrm{K}$ there is a limit of choosing the value $\mathrm{M}$. in order to avoid the overlapping between stub lines in each branches the values of $\theta_{2}$ must not exceed the value of $\theta_{1}$.

The impedance values $Z_{1}$ and $Z_{2}$ are calculated by

$$
\begin{aligned}
& Z_{1}=M Z_{o} \\
& Z_{2}=\frac{Z_{1}}{K}
\end{aligned}
$$

\section{COUPLER DESIGN AND ANALYSIS}

In the given proposed model the dielectric material is $\mathrm{fr} 4(\varepsilon \mathrm{r}=4.4)$ and height is $\mathrm{h}=1.6 \mathrm{~mm}$ for the operating frequency $=2.4 \mathrm{GHz}$. The $\frac{\mathrm{w}}{h}$ ratio is chosen as $<2$. conventional Coupler dimension are calculated using the following formulas

(i) The Width for input $(Z=50 \Omega)$ and width for branches $\left(Z_{A}=Z_{B}=70.7 \Omega\right)$ is calculated using the formula

$$
\frac{\mathrm{w}}{h}=\frac{8 \mathrm{e}^{\mathrm{A}}}{\mathrm{e}^{2 \mathrm{~A}}-2} \quad \text { for } \frac{\mathrm{w}}{\mathrm{d}}<2
$$

where, $\mathrm{A}=\frac{\mathrm{Z}}{60} \sqrt{\frac{\varepsilon_{\mathrm{r}}+1}{2}}+\frac{\varepsilon_{\mathrm{r}}-1}{\varepsilon_{\mathrm{r}}+1}\left(0.23+\frac{0.11}{\varepsilon_{\mathrm{r}}}\right)$

(ii) The effective dielectric constant $\operatorname{eff} 1(\mathrm{ZA}=50 \Omega)$ and $\varepsilon_{\text {eff2 }}$ for Branches $\left(Z_{A}=Z_{B}=70.7 \Omega\right.$ ) is calculated using

$$
\varepsilon_{\text {eff }}=\frac{\varepsilon_{\mathrm{r}}+1}{2}+\frac{\varepsilon_{\mathrm{r}}-1}{2}\left(\frac{1}{\sqrt{1+12 \frac{\mathrm{h}}{\mathrm{w}}}}\right)
$$

(iii) The Wavelength is calculated with the known $\mathrm{C}$ $=3 \mathrm{X} 10^{8} \mathrm{~m} / \mathrm{s}$ (velocity of light) and with given operating frequency $\mathrm{f}=2.4 \mathrm{GHz}$

$$
\begin{gathered}
\lambda_{0}=\frac{c}{f} \\
\lambda_{\mathrm{g}}=\frac{\lambda_{0}}{\sqrt{\varepsilon_{\text {eff } 2}}}
\end{gathered}
$$

(iv) The outer and inner radius of the Rat-Race coupler is calculated using

$$
R=\frac{3 \lambda_{g}}{4 \pi}
$$

Inner radius of the ring $(r)=\left(r-\frac{w}{2}\right)$ 
Outer radius of the ring $(\mathrm{r} 1)=\left(\mathrm{r}+\frac{\mathrm{w}}{2}\right)$

Hence the calculated parameters to design hybrid coupler at frequency $2.4 \mathrm{GHz}$ like width for input, width for branches, radius of the ring, inner radius, outer radius, and wavelength is listed in the table given below.

TABLE I. PARAMETERS FOR CONVENTIONAL HYBRID COUPLER

\begin{tabular}{|l|l|l|}
\hline S.no & \multicolumn{1}{|c|}{ Parameters } & \multicolumn{1}{|c|}{ Values } \\
\hline 1. & Frequency & $2.4 \mathrm{GHZ}$ \\
\hline 2. & Width for input & $3.0608 \mathrm{~mm}$ \\
\hline 3. & Width for branches & $1.6227 \mathrm{~mm}$ \\
\hline 4. & Radius & $16.749 \mathrm{~mm}$ \\
\hline 5. & Inner radius & $15.937 \mathrm{~mm}$ \\
\hline 6. & Outer radius & $17.560 \mathrm{~mm}$ \\
\hline
\end{tabular}

The conventional hybrid coupler is designed and simulated using the above values and shown in Figure 5.

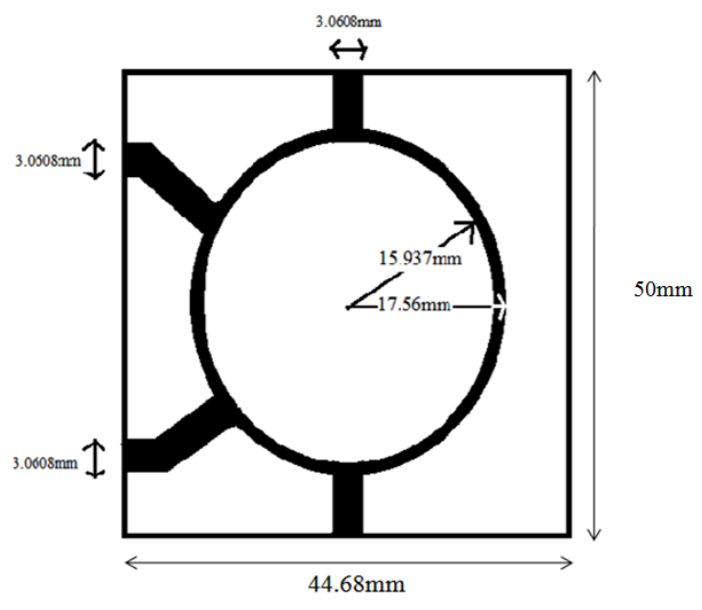

Figure 5. Conventional hybrid coupler

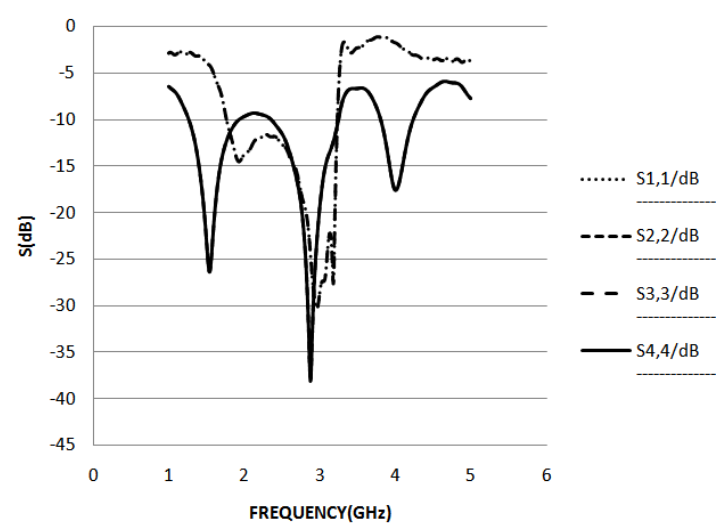

Figure 6. Simulated results for conventional hybrid coupler

$$
\left(S_{11}, S_{22}, S_{33}, S_{44}\right)
$$

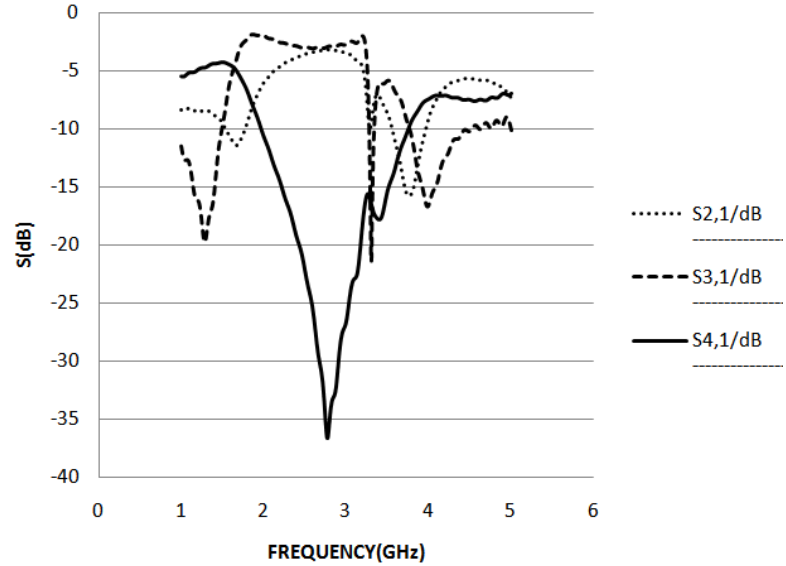

Figure 7. Simulated results for conventional hybrid coupler

$$
\left(S_{21}, S_{31}, S_{41}\right)
$$

The figure $6 \& 7$ shows the return loss parameters, Isolation and coupling coeffecients of the conventional rat-race coupler.

Hybrid coupler using T-Shape structure is designed and simulated using the formula given in section III and it is shown in Figure 8.

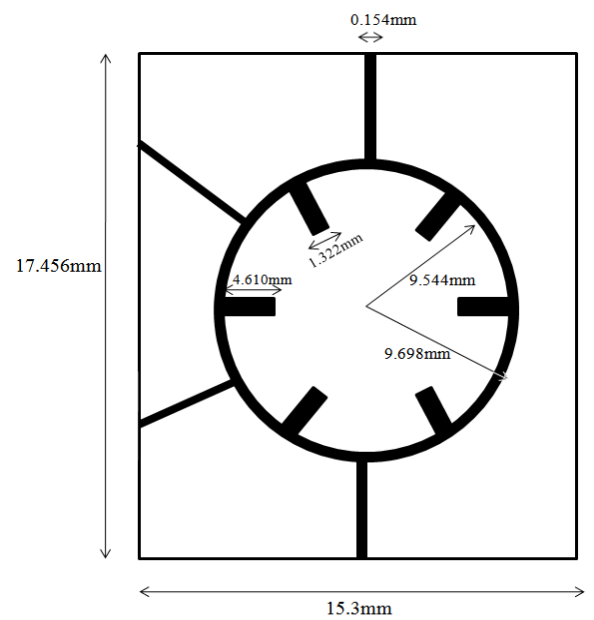

Figure 8. Reduced size hybrid coupler using T-shape structure 


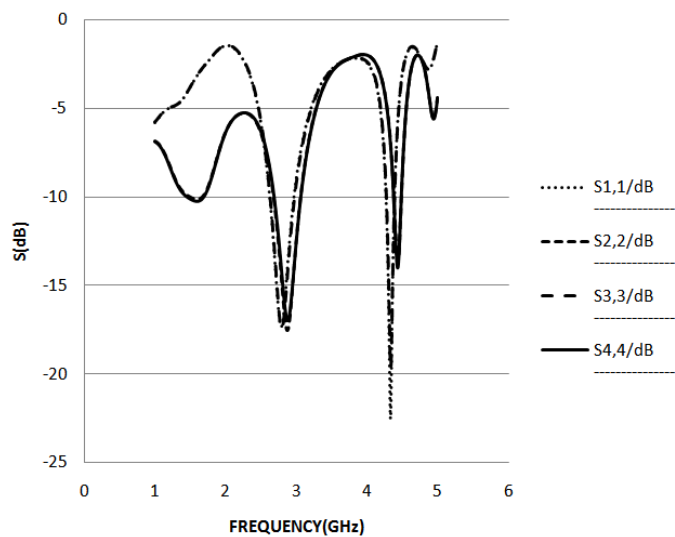

Figure 9. Simulated results for hybrid coupler using T-shape structure $\left(S_{11}, S_{22}, S_{33}, S_{44}\right)$

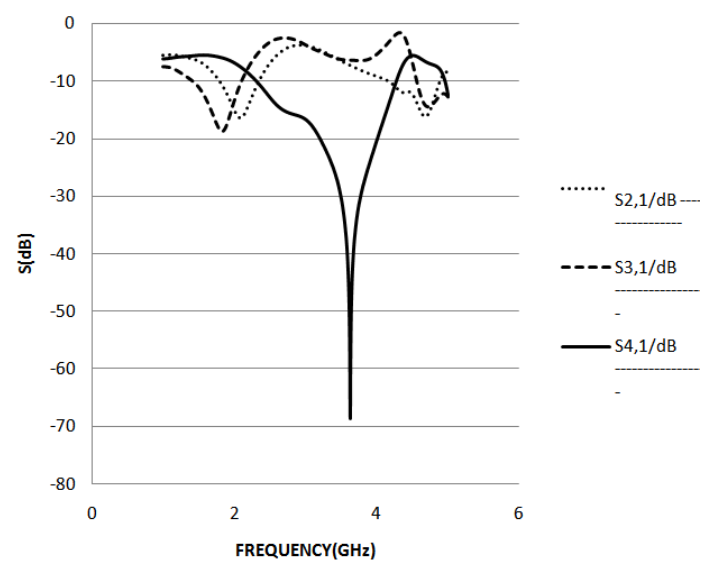

Figure 10. Simulated results for hybrid coupler using T-shape structure

$$
\left(S_{21}, S_{31}, S_{41}\right)
$$

Figure $9 \& 10$ shows the return loss parameters, Isolation and coupling coefficient of the conventional rat-race coupler using T-shape structure.

The size of conventional hybrid coupler is $44.68 \mathrm{~mm} *$ $50 \mathrm{~mm}$. By using T-shape in hybrid coupler the size is reduced to $15.3 \mathrm{~mm} * 17.456 \mathrm{~mm}$. Thus, by using $\mathrm{T}$ - shape structure $88 \%$ of size reduction has been achieved which is shown in Figure 8.

TABLE II. COMPARISON TABLE OF CONVENTIONAL HYBRID COUPLER AND CONVENTIONAL HYBRID COUPLER USING T-SHAPE STRUCTURE OF RETURN LOSS PARAMETERS

\begin{tabular}{|c|l|c|c|c|c|c|}
\hline S.No & $\begin{array}{l}\text { Types of } \\
\text { rat-race }\end{array}$ & $\begin{array}{c}\text { Freq } \\
(\mathbf{G H Z})\end{array}$ & $\begin{array}{c}\mathbf{S}_{11} \\
(\mathbf{d B})\end{array}$ & $\begin{array}{c}\mathbf{S}_{\mathbf{2 2}} \\
(\mathbf{d B})\end{array}$ & $\begin{array}{c}\mathbf{S}_{\mathbf{3 3}} \\
(\mathbf{d B})\end{array}$ & $\begin{array}{c}\mathbf{S}_{\mathbf{4 4}} \\
(\mathbf{d B})\end{array}$ \\
\hline 1. & $\begin{array}{l}\text { Conventional } \\
\text { Hybrid } \\
\text { coupler }\end{array}$ & 2.87 & - & -38.12 & -24.35 & - \\
\hline 2. & $\begin{array}{l}\text { Conventional } \\
\text { hybrid } \\
\text { coupler } \\
\text { using T- } \\
\text { shape } \\
\text { structure }\end{array}$ & 2.9 & - & - & - & - \\
\hline
\end{tabular}

TABLE III. COMPARISON TABLE OF CONVENTIONAL HYBRID COUPLER AND CONVENTIONAL HYBRID COUPLER USING T-SHAPE STRUCTURE OF ISOLATION $\left(\mathrm{S}_{41}\right)$ AND COUPLING $\operatorname{COEFFICIENT}\left(\mathrm{S}_{31}, \mathrm{~S}_{21}\right)$

\begin{tabular}{|c|l|c|c|c|c|}
\hline S.No & $\begin{array}{l}\text { Types of rat- } \\
\text { race }\end{array}$ & $\begin{array}{c}\text { Freq } \\
(\mathbf{G H Z})\end{array}$ & $\begin{array}{c}\mathbf{S}_{\mathbf{4 1}} \\
(\mathbf{d B})\end{array}$ & $\begin{array}{c}\mathbf{S}_{\mathbf{3 1}} \\
(\mathbf{d B})\end{array}$ & $\begin{array}{c}\mathbf{S}_{\mathbf{2 1}} \\
(\mathbf{d B})\end{array}$ \\
\hline 1. & $\begin{array}{l}\text { Conventional } \\
\text { Hybrid } \\
\text { coupler }\end{array}$ & 2.87 & -32.17 & -2.93 & -3.23 \\
2. & $\begin{array}{l}\text { Conventional } \\
\text { hybrid } \\
\text { coupler using } \\
\text { T-shape } \\
\text { structure }\end{array}$ & 2.9 & -16.01 & -3.02 & -3.70 \\
\hline
\end{tabular}

From table 3 and table 4 it is observed that the operating frequency $2.4 \mathrm{GHz}$ is shifted to $2.9 \mathrm{GHz}$ and the size of hybrid coupler is reduced by using $\mathrm{T}$-shape structure.

\section{CONCLUSSION}

In this paper, the conventional rat race hybrid coupler using T-shape is presented. The spurious harmonic suppression and reduction of size at desired frequency can be achieved in the rat-race hybrid coupler. Using T-shape structure in hybrid coupler reduces large amount of size than conventional rat-race hybrid coupler. The conventional hybrid coupler is $44.68 \mathrm{~mm} * 50 \mathrm{~mm}$. by using $\mathrm{T}$-shape in hybrid coupler the size is reduced to $15.3 \mathrm{~mm} * 17.456 \mathrm{~mm}$. By using T- shape structure $88 \%$ of size reduction has been achieved.

\section{REFERENCES}

[1] Kai-Xu Wang, Xiu Yin Zhang,Shao Yong Zheng, and Quan Xue"Compact Filtering Rat RaceHybrid With Wide Stopband",Vol. 63,No.8,August 2015.

[2] Y. J. Sung, C. S. Ahn, and Y.-S. Kim , "Size Reduction and Harmonic Suppression of Rat-Race Hybrid Coupler Using Defected Ground Structure" IEEE microwave and wireless components letters Vol.14,No.1,January 2004,p.7-9.

[3] "Advanced Microstrip Trainer Kit User's Manual,"The Scientific Instruments Co. ltd., IIT Delhi.

[4] Sanjay Bhilegaonkar, Ashwinikumar Dhande, "Monopulse Comparator Network System with Hybrid Rings", The 19th Asia Pacific conference on Communication APCC2013,Bali-Indonisia,August 2013,p.562-563.

[5] Samuel Y. Liao,Microwave Devices and Circuits,3rd edition,New Jersey:Prentice Hall,p.147-148.

[6] Qing He, Yinghong Wen, Song Chen, and Kai Wang”A Compact Uniplanar Rat-Race Coupler with Arbitrary Power Division Ratio and Harmonics Suppression”, ,Vol. 52, p.71,March 2015. 
